\title{
Design of the seam tracking system based on wireless network environment
}

\author{
Guorui Wu \\ Shenyang Aerospace University, Shenyang110136, China \\ guorui@163.com
}

Keywords: WiFi, STM32F405/F373, Remote control system, Seam tracking

\begin{abstract}
The automatic, intelligent and networking of welding process is the trend of the development of the welding. With improvement of welding equipment, to achieve the process of seam tracking wireless WiFi network control and data sharing, this paper employ the embedded connection between the microcontroller STM32F405/F373 and Wizfi210 wireless modules, control system based on embedded wireless WiFi communications, remote control system of welding seam tracking and weld seam tracking is developed, which also enables welding control in complex environments.
\end{abstract}

\section{Introduction}

Using automatic welding in the welding production, it can improve the efficiency of welding and increase the welding production on the premise of guarantee the quality of welding. At the same time, it can also reduce the labor intensity of welding operators [1]. In terms of electromagnetic sensors, In order to obtain relatively strong sensor signal, some foreign scholars have adopted many methods to increase the strength of magnetic field, such as sensor array, multi-frequency excitation sensor, pulse excitation sensors and so on[2-5]. In terms of wireless communication technology, J.D.C ullen used wireless transmission data in the process of spot welding [6].And through the analysis of computer processing, it realized the networked control in the process of spot welding. Marcus Vinicius Ribeiro Machado used MoSo WiFi communication in the process of arc welding[7], at the same time it can wireless monitor voltage, current and wire feed speed signals in the process of arc welding to make welding process control.

Based on this background, we design a remote control seam tracking system in this paper. After hardware circuit design, each module function was achieved by software debugging. Weld seam tracking system based on STM32F405 / F373 micro-controller embedded connection with Wizfi210 wireless module, it realizes wireless WiFi network control and data sharing in the process of seam tracking.

\section{Hardware design of seam tracking controller}

The hardware circuit design of seam tracking controller mainly includes the following three aspects. First, we should choose the right micro-controller to meet the system requirements. Next, it is the layout of the power supply for the whole control system to get a stable power supply environment. To the design of stepper motor sports organizations at the same time, it can realize the adjustment of the welding torch location. Finally, it is the improvement of sensor input and output signal processing circuit.

Power controller design. In this paper, it uses $24 \mathrm{v}$ input as the system power supply voltage. The system is not only to export control signal, but also to collect analog signal. Then we need to improve the anti-jamming and security performance of power supply. Power supply design is shown as figure 1 , each independent power module uses a regulated power supply power to supply, respectively. 


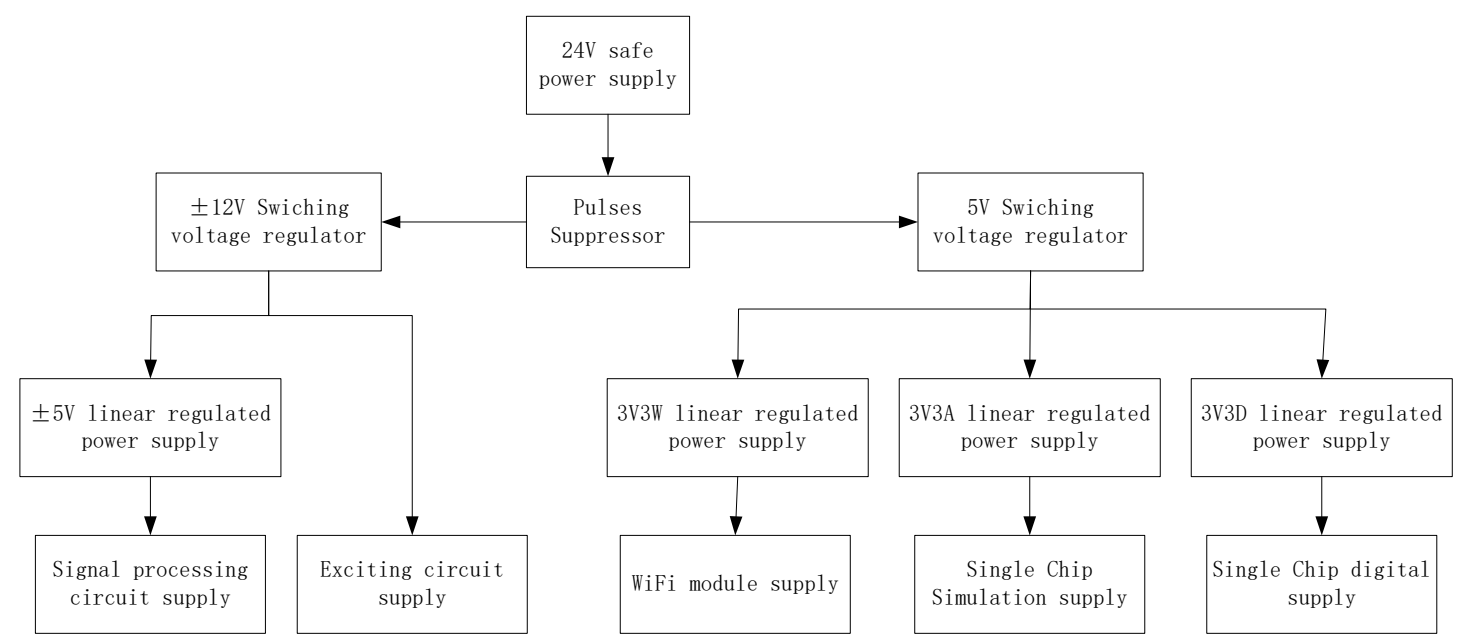

Fig. 1 Power supply design

The input processing of $24 \mathbf{v}$ power supply voltage. This system uses $24 \mathrm{v}$ voltage as the input voltage, which makes the $24 \mathrm{v}$ power supply easy to be disturbed by grid voltage and other high frequency signal interference.

The power of operational chip. The $\pm 12 \mathrm{v}$ regulator output voltage is divided into two parts. One part is used as the power for the excitation op-amp voltage. The other part by linear voltage stabilizer to make a $\pm 5 \mathrm{v}$ voltage regulator. It can not only reduce the system power consumption, but also can further eliminate type switch voltage ripple to reduce the impact on the signal acquisition.

The MCU power supply. By calculation the power of MCU, $24 \mathrm{~V}$ power supply power $5 \mathrm{~V}$ $\mathrm{DC} / \mathrm{DC}$ electrical source which is only $3 \mathrm{~W}$ is used. Through the linear voltage source voltage it makes $5 \mathrm{v}$ to $3.3 \mathrm{~V}$ voltage into 3 road, including the Wizfi210 module power supply, the other are single chip microcomputer digital power and analog power respectively.

Drive circuit design of stepper motor .For stepper motor, single-chip microcomputer need two way IO ports with timer function, which produce a certain frequency pulse signals, respectively to drive stepper motor clockwise and counterclockwise rotation. To make a further improve based on STM32F405 single-chip microcomputer control system, stepping motor driver circuit is shown as figure 2 .

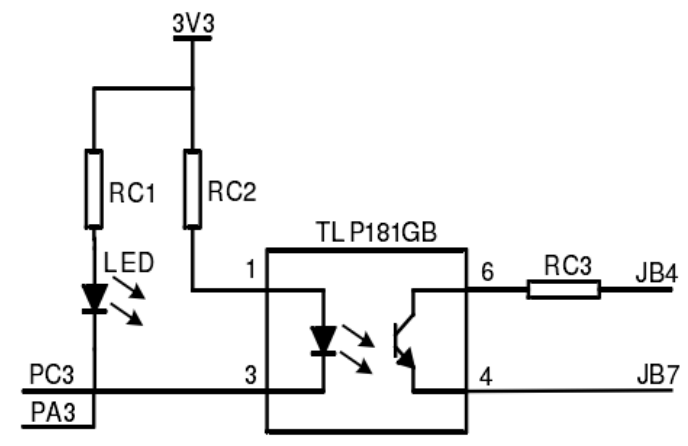

Fig. 2 Stepper motor drive circuit

On aspects of motor drive, TLP181GB is instead of triode. It makes the control system isolate with the outside world to enhance the anti-jamming performance of the system. Compared with before, driving signal inputs are connected to the two single chip microcomputer timer IO mouth respectively, one is for motor drive, the other is for count number. In the paper, while we design the LED lights, the stepper motor driver status display is also guaranteed.

The sensor signal circuit design.Signal processing circuit is shown as figure 3 , it makes the sine wave signal produced by single chip microcomputer DA function to deep-buried electrode, filtering and amplification. And it converts the signal 0-3.3 V pulse dc to the standard sine wave ac signal. The final output of the excitation signal amplitude is to $\pm 10.5 \mathrm{~V}$, the frequency highest is $4 \mathrm{KHZ}$. 


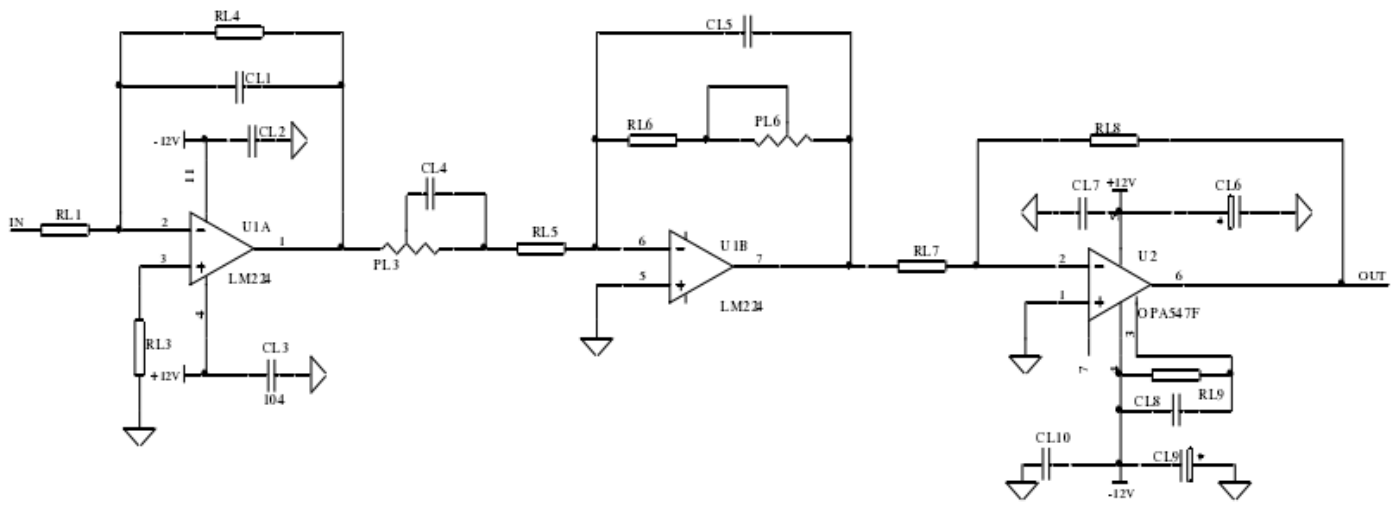

Fig. 3Excitation signal processing circuit

The software design and function implementation of seam tracking controller.The software design of seam tracking controller mainly includes the communication configuration, sensors secondary excitation signal processing, signal processing and simulation DA, timer, SDADC analog acquisition program design, etc. Processes is shown in figure 4.

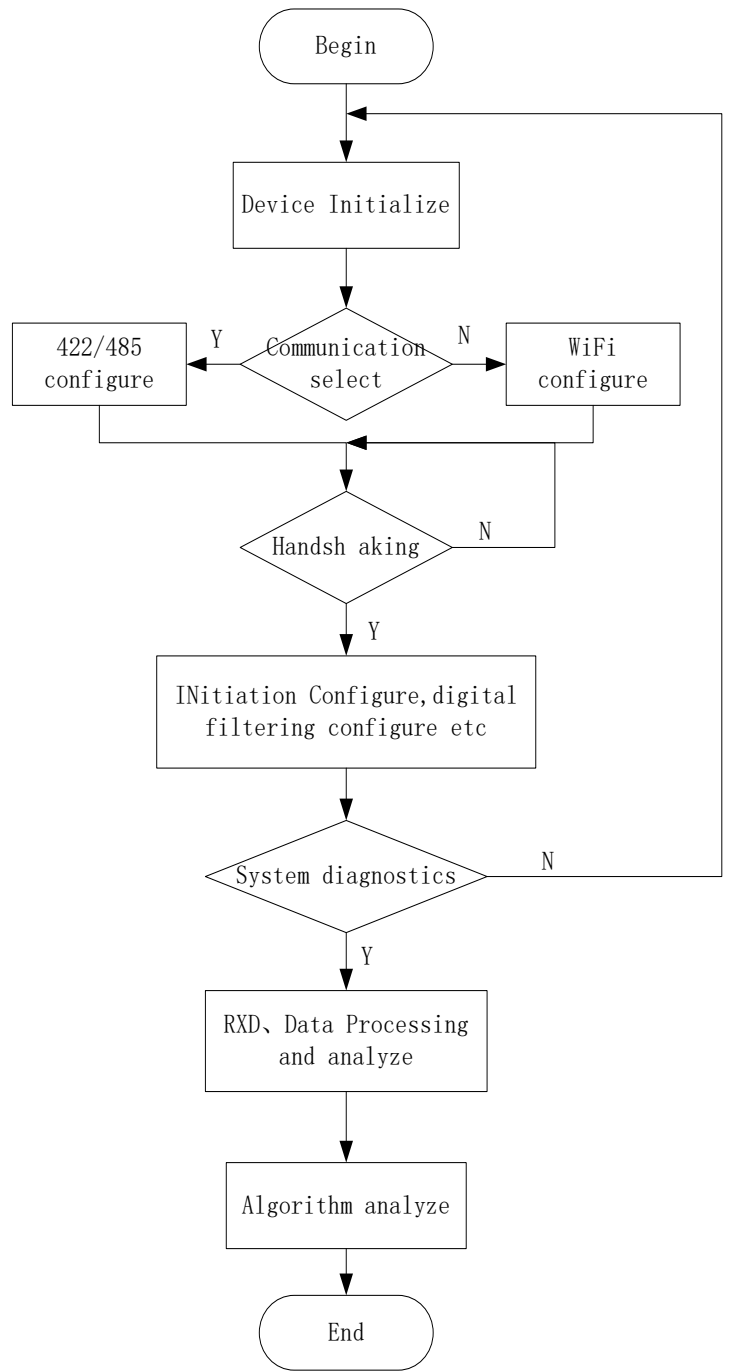

Fig. 4The procedure flow charts of seam tracking controller

On the basis of successful communication handshake to setup and adjustment of each function module, and then entered the stage of data reception and judgment, and the main program is used as circular scanning mechanism. After each inspection system working condition, once the abnormal work, it immediately resets initialization. 


\section{Design of embedded wireless WiFi.}

The hardware design. The hardware design of embedded wireless module connected to the MCU s shown as figure 5, namely, Wizfi210 communication function IO connected with single-chip microcomputer serial port function IO.

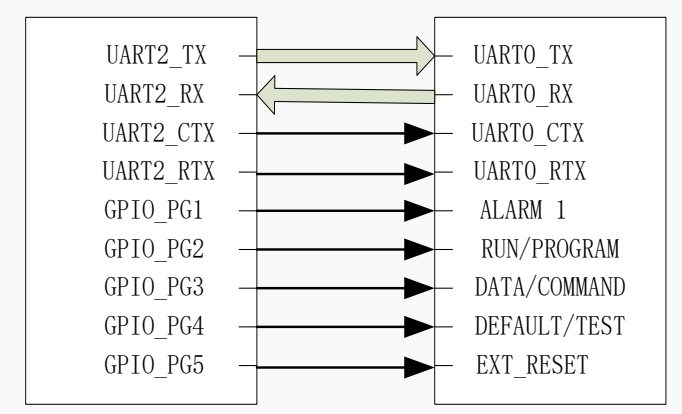

Fig. 5 Embedded connection diagram of wireless module and micro-controller

The software design. Communication between MCU and WiFi module. Firstly, through the $\mathrm{C}$ language to set the AT command for wireless module, selecting communication mode and setting network communication parameter. And then the data via a serial port turn WiFi or WiFi turn a serial port to exchange information.

\section{Conclusions}

In this article, we realize the wireless WiFi network communication of seam tracking device and control device. By remote control box, it can accurately gather the switch or analog signal of the remote control box panel through setting the seam tracking controller operation parameters. And it can real time up a data transfer on board and realize data sharing at the same time.

\section{References}

[1] Ben Shan Chen, etc., Modern control technology in welding process (Harbin industrial university press, Chinese 2001, p.13-15.

[2] Tomasz Ch, Masato E,Rysaard S,et.al. Natural Crack Recognition Using Inverse Neural Model and Multi-Frequency Eddy Current Method, (2001) No.4, p.2797-2799.

[3]Yoshiaki N, Toshiyuki Tetsuya U,et.al, Identification of Multiple Cracks from Eddy-Current Testing Signals with Noise Sources by Image Processing and Inverse Analysis,(2004) No.2, p.1112-1115.

[4]Kreutzbruck M.V, Allweins K, Ruhl T, et.al. Defect Detection and Classification using a SQUID based Multiple Frequency Eddy Current NDE System, (2001) No.1, p.1032-1037.

[5]X.Jian, S.Dixon. Enhancement of EMAT and Eddy Current Using A Ferrite Back-plate,(2007)No.136, p.132-136.

[6] J.D. Cullen, A, Mason, M. Al-Jader,etc. Multi-Sensor Spot Welding Monitor using WirelessSensor Network Technology(2011), p.806-810.

[7] Marcus Vinícius Ribeiro Machado1, Carolina Pimenta Mota1, Roberto Mendes Finzi Neto1,etc, Embedded System for Wireless Signal Monitoring During Arc Welding with Technological Approach,(2012), p.147-157. 